\title{
Yaşlılarda Bilişsel Fonksiyonun Korunması ile İlişkili Diyet Modelleri
}

\author{
Dietary Patterns Associated with the Maintenance of Cognitive Function in Elderly
}

\author{
Ebru Melekoğlư ${ }^{1}$ Neslişah Rakıcıoğlu²
}

Geliş tarihi/Received: $10.01 .2020 \bullet$ Kabul tarihi/Accepted: 03.10.2020

\section{ÖZET}

Beslenme, yaşlılarda bilişsel bozukluk ve demans riskini azaltabilecek en önemli yaşam tarzı faktörüdür. Epidemiyolojik çalışmalar, bilişsel fonksiyonun azalması ve demansın önlemesinde veya geciktirilmesinde Akdeniz, Hipertansiyonun Önlenmesi için Beslenme Yaklaşımı (DASH) ve Nörodejeneratif Gecikme için Akdeniz-DASH Müdahalesi (MIND) diyeti gibi sağlıklı diyet modellerinin olası koruyucu etkilerini desteklemektedir. Deniz ürünleri, sert kabuklu yemişler, sebze-meyve tüketimi ile bilişsel durum arasında koruyucu bir ilişki olduğunu ortaya koyan sınırlı sayıda klinik araştırma bulunmaktadır. Bilişsel sağlığın korunmasında sağlıklı diyet modellerinin tek bir besin ya da besin grubuna göre daha etkili olduğu görüşü öne çıkmaktadır. Yaşlılarda bilişsel sağlığın korunmasında sadece yaşlılık döneminde değil yaşam boyunca sağlıklı beslenmenin benimsenmiş olması önemlidir. Bilişsel fonksiyonun azalması ve demans ile ilgili belirtiler ortaya çıkmadan önce bilişsel yaşlanmanın yavaşlatılması ve önlenmesinde sağlıklı beslenmenin sağlanması gerekmektedir. Bu sebeple yaşlılarda bilişsel sağlığın korunmasında etkili olan diyet modelleri ve etki mekanizmalarını açıklayacak çalışmalara ihtiyaç duyulmaktadır. $\mathrm{Bu}$ derleme makalede, yaşlı bireylerde bilişsel fonksiyonun korunmasında etkili olabilecek diyet modelleri güncel bilgiler ışı̆̆ında incelenmiştir.

Anahtar kelimeler: Bilişsel fonksiyon, yaşlanma, diyet modeli, Akdeniz diyeti, DASH diyeti, MIND diyeti

\begin{abstract}
Nutrition is the most important lifestyle factor that can reduce the risk of cognitive impairment and dementia in elderly. Epidemiological data support the possible protective effects of Mediterranean, Dietary Approach to Stop Hypertension (DASH) and Mediterranean-DASH Intervention for Neurodegenerative Delay (MIND) dietary patterns, which are healthy dietary models in preventing or delaying cognitive decline and dementia. Limited number of clinical studies has demonstrated a protective relationship between cognitive outcomes and consumption of seafood, nuts, vegetables and fruits. It is suggested that healthy dietary models are more effective than a single food or food group in preventing cognitive health. In elderly adults, it is important to maintain healthy nutrition not only in old age but throughout the life, to slow down and prevent cognitive aging before symptoms of cognitive decline and dementia occur. Therefore, more clinical research is required with larger sample sizes and longer follow-up times to determine the dietary factors and their underlying mechanisms related cognitive function in aging populations. In this review, dietary models that can be effective in preventing cognitive function in elderly adults were examined in the light of the current knowledge.
\end{abstract}

Keywords: Cognitive function, aging, dietary pattern, Mediterranean diet, DASH diet, MIND diet

1. İletişim/Correspondence: Hacettepe Üniversitesi, Sağlık Bilimleri Fakültesi, Beslenme ve Diyetetik Bölümü, Ankara, Türkiye

E-posta: ebru.melekoglu@hacettepe.edu.tr • 단 https://orcid.org/0000-0002-2342-221X
2. Hacettepe Üniversitesi, Sağlık Bilimleri Fakültesi, Beslenme ve Diyetetik Bölümü, Ankara, Türkiye

(1) https://orcid.org/0000-0001-8763-7407 


\section{GíRiş}

Dünya Sağlık Örgütü (DSÖ), 60 yaş üzeri nüfusun toplam nüfus içindeki oranının 2015 yılında \%12 olduğunu, 2050 yılında ise \%22'ye kadar çıkabileceğini açıklamıştır (1). Türkiye İstatistik Kurumu'nun 2018 yllı verilerine göre 65 yaş üzeri nüfusun toplam nüfus içindeki oranı \%8.8'dir (2). Günümüzde yaşlı nüfusun artışına bağlı olarak yaşlanmayla ilişkili bilişsel fonksiyonun azalmasıönemlibir toplum sağlığısorunu haline gelmiştir (1). Bilişsel fonksiyonun azalmasında yaş, aile öyküsü ve Apolipoprotein E $\varepsilon 4$ (APOE-є4) allel genlere sahip olmak gibi genetik yatkınlık durumu değiştirilemeyen risk faktörlerindendir. Ancak diyabet, obezite, hipertansiyon ve hiperlipidemi gibi kardiyovasküler risk faktörleri, sağlıksız beslenme, sedanter yaşam tarzı, sigara, eğitim durumu, sosyal ya da mental uyaran eksikliği bilişsel fonksiyonun korunmasinda ya da demansin önlenmesinde değiştirilebilir risk faktörlerindendir (3). Toplum tabanlı veriler, dünya genelinde Alzheimer hastalığı vakalarının 1/3'ünün potansiyel olarak değiştirilebilir risk faktörleriyle ilişkili olduğunu göstermiştir (4).

Bilişsel fonksiyonun bozulmasında, Akdeniz diyetine uyumun az olması, D vitamini yetersizliği, yetersiz n-3 yağ asitleri alımı ya da yetersiz balık tüketimi, B grubu vitaminlerinin, diyet polifenollerinin ve antioksidan besin ögelerinin yetersiz alımı ve alkolün fazla tüketilmesi beslenme ile ilgili potansiyel risk faktörleridir (5). Beslenme; bilişsel bozukluk ve demans riskini azaltabilecek en önemli yaşam tarzı faktörü olmasının yanı sıra diyabet, kardiyovasküler hastalıklar gibi demans riskini artıran birçok hastalığın önlenmesinde de en önemli stratejidir (3).

Yaşlı bireylerde besin, besin ögesi ve bilişsel fonksiyon arasındaki koruyucu ilişkinin ortaya konduğu gözlemsel ve klinik araştırmalardan elde edilen veriler halen tartışmalıdır (5). Akdeniz ve Hipertansiyon Önlenmesi için Beslenme Yaklaşımı (Dietary Approach to Stop Hypertension-DASH) diyeti gibi sağlıklı diyet modellerinin bilişsel fonksiyon üzerine koruyucu etkisi tek başına bir besin ya da besin ögesine klyasla daha güçlüdür. $\mathrm{Bu}$ diyet modellerinin içeriğinde bulunan birçok besin bileşeninin sinerjik ve kümülatif faydalı etki gösterdikleri ileri sürülmektedir (5,6). Bu derlemede, yaşlı bireylerde bilişsel fonksiyonun korunmasında etkili olabilecek besin ögesi, besin ve diyet modellerini araştıran gözlemsel ve klinik çalışma sonuçlarının derlenmesi amaçlanmıştır. Bu kapsamda Akdeniz, DASH ve Nörodejeneratif Gecikme için Akdeniz-DASH Müdahalesi (Mediterranean-DASH Intervention for Neurodegenerative Delay-MIND) diyet modelleri ve bu diyet modellerinde vurgulanan besin ve besin ögelerinden bahsedilmiş, yeterli kanıt bulunmayan ve çelişkili sonuçları olan diyet modelleri ise yazının kapsamına dahil edilmemiştir.

\section{Nöroprotektif Diyet Modelleri}

Sebze ve meyveler, tam tahillar, sert kabuklu yemişler ve balık tüketiminin yüksek olduğu; kırmızı et, kümes hayvanları, yüksek yağlı süt ürünleri ve işlenmiş besinlerin ise sınırlı miktarda tüketildiği diyet modellerinin daha iyi bilişsel fonksiyon ve daha düşük demans riskiyle ilişkili olduğu bulunmuştur (7). Besin ögelerinden E vitamini, dokosaheksaenoik asit (DHA) ve folatın yeterli alımı ve doymuş yağ tüketiminin azaltılmasının bilişsel sağlığın korunmasında etkili olduğuna dair güçlü kanitlar vardır $(5,8)$. Hücre kültürü ve hayvan modellerinde yapılan çalışmalarda, $\mathrm{C}$ vitamini ve polifenoller gibi antioksidan bileşenlerin amiloid $\beta$ $(\mathrm{A} \beta)$ birikimi, lipit peroksidasyonu, mitokondriyal disfonksiyon, nörotoksisite, dendrit dejenerasyonu ve nöroinflamasyonu azaltan nöroprotektif etkileri gösterilmiştir $(9,10)$. Bilişsel ve metabolik fonksiyonun korunmasinda fitokimyasallar, antioksidanlar ve vitaminlerden zengin olan yeşil yapraklı sebzeler, meyveler, tam tahıllar ve sert kabuklu yemişlerin yer aldığı sağlıklı ve dengeli diyet modelleri önemli rol oynamaktadır (6). Bu diyet modellerinden Akdeniz, DASH ve MIND diyetlerinden Tablo 1'de sirasiyla bahsedilmektedir (7). 
Tablo 1. Nöroprotektif diyet modelleri ve içeriklerinde bulunan besin ögesi ve besin grupları (7)

\begin{tabular}{|c|c|}
\hline Besin ögesi & Besin grupları \\
\hline 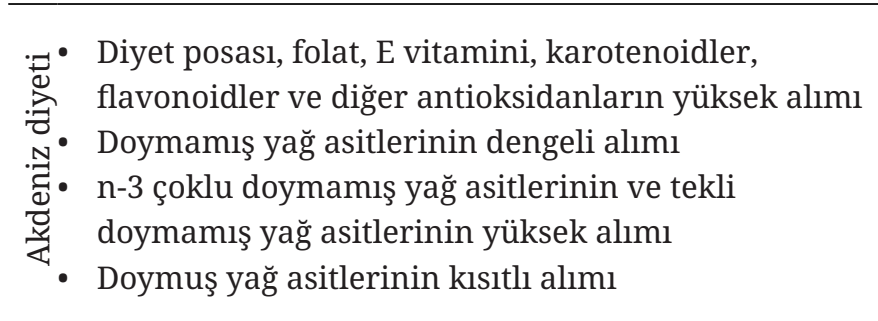 & $\begin{array}{l}\text { - Sebze-meyve, tam tahıllar ve zeytinyağı tüketiminin } \\
\text { artırılması } \\
\text { - Fermente süt ürünleri, sert kabuklu yemişler, taze otlar veya } \\
\text { baharatların günlük tüketimi } \\
\text { - Kırmızı et yerine bitkisel proteinlerin (kurubaklagiller) ve } \\
\text { deniz ürünlerinin tercih edilmesi } \\
\text { - Orta düzeyde şarap tüketimi }\end{array}$ \\
\hline 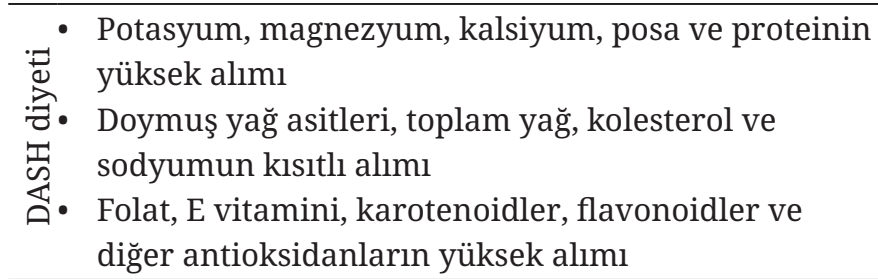 & $\begin{array}{l}\text { - Sebze-meyve, az yağlı süt ürünleri ve tam tahılların } \\
\text { tüketiminin artırılması } \\
\text { - Kırmızı et yerine yağsız beyaz etlerin tercih edilmesi } \\
\text { - Doymuş ve trans yağ asidi, sodyum ve şeker içeriği düşük } \\
\text { besinlerin tercih edilmesi }\end{array}$ \\
\hline 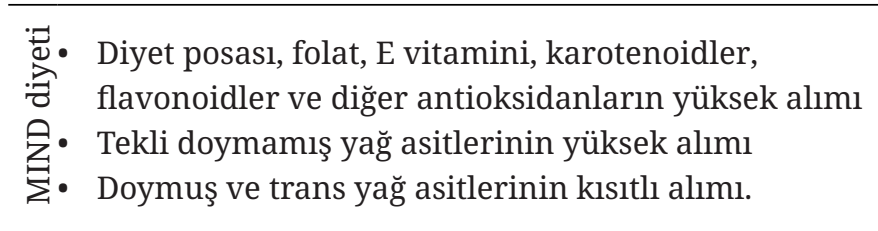 & $\begin{array}{l}\text { - Yeşil yapraklı sebzeler, diğer sebzeler, çilekgiller, sert } \\
\text { kabuklu yemişler, kurubaklagiller, tam tahıllar, balık, kümes } \\
\text { hayvanları, zeytinyağı ve şarap tüketiminin artması } \\
\text { - Kırmızı et, tereyağı, margarin, peynir, hamur işleri, tatlılar } \\
\text { ve kızartmaların tercih edilmemesi }\end{array}$ \\
\hline
\end{tabular}

DASH: Hipertansiyonun Önlenmesi için Beslenme Yaklaşımı

MIND: Nörodejeneratif Gecikme için Akdeniz-DASH Müdahalesi

\section{Akdeniz Diyeti}

A, C, E vitamini, $\beta$-karoten, flavanoidler, $n-3$ çoklu doymamış yağ asitleri gibi besin ögelerinin bilişsel fonksiyon üzerine olumlu etkileri bazı gözlemsel çalışmalarda gösterilmiştir (11,12). Ancak bilişsel sağlığın korunmasında bu besin ögelerinin tek başına değil, bütünsel diyet yaklaşımıyla ele alındığında daha etkili olduğu ileri sürülmektedir (8). Özellikle yaşlı popülasyonda bilişsel sağlıkla ilişkili diyet modelleri içerisinde sinerjik ve kümülatif etkilerine dair en güçlü kanıt bulunan Akdeniz diyet modelidir $(5,6)$. Akdeniz diyeti, zeytinyağından gelen tekli doymamış yağ asitleri, balık ve bitkisel kaynaklardan gelen n-3 yağ asitleri, sebze, meyve, sert kabuklu yemişler ve tam tahılların yüksek tüketimi ve kırmızı et ve süt ürünlerinin sinırlı tüketimi ile karakterizedir (13).

Akdeniz ülkelerinde yapılan kohort çalışmalarında Akdeniz diyetine yüksek uyumun yaşlı bireylerde daha iyi bilişsel sağlıkla ilişkili olduğu ortaya konmuştur $(14,15)$. Akdeniz ülkeleri dışında yapılan gözlemsel çalışmalarda ise Akdeniz diyetine uyum ve bilişsel fonksiyon ile ilişkili tutarlı sonuçlar bulunmamaktadır (16,17). Avrupa Prospektif Kanser ve Beslenme Araştırmasından (European Prospective Investigation into Cancer/EPIC-Norfolk) elde edilen veriler; Birleşik Krallık’ta bulunan, 48-92 yaş aralığında 8009 yetişkinin 13 yll takibi sonucunda, Akdeniz diyetine uyum skorunda her bir puanlık artışın bilişsel yaşlanmayı ortalama 1.7 yıla eşdeğer olarak geciktirdiğini göstermiştir (16). Avustralya'da yapılan bir kohort çalışmasında ise 4 yll boyunca takip edilen 60-64 yaş grubu bireylerde Akdeniz diyetine uyumun hafif bilişsel bozukluk üzerinde koruyucu bir etkisi olmadığını göstermiştir (17). Bilişsel sağlığın; coğrafik, kültürel ve sosyodemografik kapsamda kompleks süreçlerden etkilendiği unutulmamalıdır. Akdeniz ülkelerinde sosyal iletişim, toplumsallık duygusu, geleneksel pişirme yöntemleri kullanılarak pişirilen, hızlı ve ekran önünde yemek yeme yerine yavaş bir şekilde, aile ya da arkadaşlarla birlikte tüketilen öğünler, Akdeniz ülkeleri dışında yapılan çalışmaların tutarsız sonuçlarını kısmen açıklayabilmektedir (18).

Gözlemsel çalışmalarla ortaya konan Akdeniz diyeti ile bilişsel fonksiyon arasındaki pozitif 
ilişki, iki klinik çalışma ile desteklenmiştir $(19,20)$. PREDIMED (Prevención con Dieta Mediterránea) çalışması verilerinden çekilen ve 4.1-6.5 yıl takip sürelerine sahip bu iki çalışmada, katılımcılar üç gruba ayrllarak bir gruba Akdeniz diyet modelinin yanı sıra 30 g/gün sert kabuklu yemiş, diğer bir gruba ise Akdeniz diyet modelinin yanı sıra bir litre/ hafta zeytinyağı tüketmeleri sağlanmış, kontrol grubuna ise sadece diyet yağını azaltma önerisinde bulunulmuştur. Her iki klinik çalışma sonucunda da Akdeniz diyeti alan gruplarda (Akdeniz diyeti + 1 L/hafta zeytinyağı ve Akdeniz diyeti + 30 g/gün kabuklu yemiş) kontrol grubuna göre daha yüksek bilişsel skor gözlenmiştir (19,20). Bununla birlikte, bu çalışmalarda, zeytinyağı ve sert kabuklu yemiş tüketimi Akdeniz diyeti ile birlikte değerlendirildiği için bu besin gruplarının bilişsel fonksiyon üzerine etkileri Akdeniz diyetinden bağımsız olarak ortaya konulamamıştır. Avustralya'da sadece altı aylık takip süresince yapılan ve daha az sayıda katılımcıya sahip bir klinik çalışmada ise Akdeniz diyeti uygulayan ve normal diyet alışkanlıklarını sürdüren kontrol grubu karşılaştırıldığında, katılımcılara uygulanan nöropsikolojik test performansında önemli bir fark gözlenmemiştir (21). Akdeniz diyet modeli bileşenlerinin bilişsel fonksiyon üzerine etkilerine dair çalışmalar aşağıda incelenmiştir.

Zeytinyağı: Doğal sızma zeytinyağı, Akdeniz diyet modelinin temel taşını oluşturmaktadır. İçerdiğinde bulunan tekli doymamış yağ asitlerinden oleik asitin antioksidan, anti-inflamatuvar, amiloid plakların birikiminde azalma, bilişsel fonksiyonda iyileşme gibi nöroprotektif ve kardiyoprotektif etkileri ileri sürülmektedir (8). Zeytinyağı içerisinde bulunan minör bileşenlerden oleuropein ve oleokantal gibi fenolik bileşiklerin Alzheimer Hastalığı deneysel modellerinde serbest radikallerin süpürülmesi, antiaterojenik, antitrombotik ve anti-inflamatuvar etkiler göstererek umut verici sonuçlar elde edilmiştir. Fenolik bileşenlerin zeytin çeşidi, ağaç yaşı, tarım teknikleri, olgunluk derecesi, toprak tipi ve bileşenleri, iklim, işleme tekniği ve depolama koşullarına göre farklılık gösterebileceği unutulmamalıdır (22).
Zeytinyağı içeriğinde bulunan biyoaktif bileşenlerin bilişsel sağlı̆̆ın korunmasındaki işlevleri ve etki mekanizmalarına dair daha çok çalışmaya ihtiyaç vardır.

Sebze ve meyveler: Yapılan gözlemsel çalışmalarda sebze ve meyve tüketimi birlikte incelenmiş ve toplam sebze-meyve tüketimi arttıkça demans veya Alzheimer Hastalığı riskinin azaldığı gösterilmiştir $(23,24)$. Bilişsel fonksiyonda azalma ve demans riski açısından özellikle folat ve flavonoid kaynağı olan yeşil yapraklı sebzeler ve iyi bir flavonoid kaynağı olan çilekgiller daha öne çıkmaktadır (5). Antioksidan ve anti-inflamatuvar özelliklere sahip olan flavonoidlerin, nöroinflamasyon ve nöronal hücre ölümünü önleyerek nöroprotektif etki gösterebileceği ileri sürülmektedir (8). Folat, homosistein metabolizmasında anahtar role sahip olup yetersizliği durumunda bilişsel fonksiyonda azalma, vasküler demans ve Alzheimer Hastalığı ile ilişkilendirilen hiperhomosisteinemiye neden olmaktadır (5). Morris et al. (25) yürüttüğü uzunlamasına bir çalışmada, 58-99 yaş aralığındaki bireyler (n=960) 4.7 yll takip edilmiş ve çalışma sonucunda yeşil yapraklı sebze tüketiminin bilişsel fonksiyonun korunmasında olumlu etkisi olduğu bulunmuştur. Aynı çalışmada yeşil yapraklı sebzelerde bulunan biyoaktif bileşenlerden fillokinon, lutein, folat, a-tokoferol, nitrat, kamferol alımları yüksek olanlarda da bilişsel yaşlanma daha yavaş bulunmuştur. Kesitsel ve nüfus tabanlı bir çalışmada 65 yaş ve üstü bireylerin sebze-meyve tüketimleri değerlendirilmiş ve DSÖ’nün önerilerine uygun olarak günlük en az beş porsiyon ( $\geq 400 \mathrm{~g} /$ gün) sebzemeyve tüketenlerde bilişsel bozukluk prevalansının \%47 daha az olduğu saptanmıştır (26).

Balık: Balık ve deniz ürünlerinin içeriğinde bulunan başta n-3 yağ asitleri olmak üzere A ve B grubu vitaminler nöroprotektif etki göstermektedir (5). Özellikle yağlı balıklar ve balık karaciğerinin içerdiği D vitamini; inflamasyon veya glukokortikoidlerin neden olduğu nörodejenerasyondan korumasının yanı sıra $A \beta$ birikiminde azalma ve klirensinde artma olmak üzere birçok nörobiyolojik yolakla ilgilidir (5). Zhang et al. (27) yaptığı 2-21 yll takip süresine sahip 
21 kohort çalışmasından oluşan bir meta-analizde; haftada bir balık tüketiminin (105 g) ve diyetle DHA alımında $0.1 \mathrm{~g} /$ gün artışın demans ve Alzheimer hastalığı riskini azalttığı sonucuna varılmıştır. Balık tüketimi ile bilişsel sağlığın korunması arasında güçlü korelasyon olup, bu nedenle düzenli bir şekilde balık tüketilmesi önerilmektedir. Ancak, ton balığı ve kılıç balığı gibi besin zincirinin üst basamağında olan balıklarda yaygın bulunan metilmerkür, ağır metaller ve organoklorin pestisitler, polisiklik aromatik hidrokarbonlar, poliklorlu bifeniller, dioksinler ve dibenzofuranlar gibi kirleticiler nörotoksik özellik taşımaktadır. Bu sebeple düzenli balık tüketimi önerilirken, güvenli ve kontrollü besin seçiminin sağlanması da bir o kadar önemlidir (28).

Kırmızı şarap: Üzüm ve şarapta bulunan bir polifenol olan resveratrol, antioksidan ve anti-inflamatuvar etki göstermektedir. Üzümden şarap yapımında mayalanma sürecinde resveratrol konsantrasyonu artmaktadır (29). Özellikle kırmızı şarabın orta düzeydeki tüketiminin bilişsel fonksiyonda azalma ve demans gelişiminde koruyucu olabileceği öne sürülmektedir (29). Yapılan uzun süreli gözlemsel bir çalışmada, kırmızı şarap tüketimi ile bilişsel fonksiyonun korunması arasında pozitif yönde bir ilişki olduğu, bira ve distile içkilerin dahil olduğu yüksek toplam alkol tüketiminin ise olumlu bir etkisinin olmadığı gibi, demans riskini de artırdığı gösterilmiştir (30).

Kurubaklagiller, sert kabuklu yemişler, tam tahıllar: Çin'de yapılan kesitsel bir çalışmada günde 50 gram kurubaklagil tüketen yaşlı yetişkinlerde, bilişsel performans skorunun daha yüksek olduğu gözlenmiştir. Bilişsel olarak sağlıklı olan yaşlı bireylerde günlük kurubaklagil tüketiminin hafif bilişsel bozukluk tanısı almış yaşlı bireylere göre daha yüksek olduğu, tam tahıl tüketimleri arasında ise fark olmadığı gösterilmiştir (31). Ortalama yaşı 74 yıl olan 16010 kadının altı yıl takibi sonucunda sert kabuklu yemişlerin uzun dönem yüksek miktarda tüketiminin ( $\geq 5$ porsiyon/hafta; 28 g=1 porsiyon) daha iyi bilişsel fonksiyonla ilişkili olduğu görülmüştür. Sert kabuklu yemiş tüketim sıklığı en yüksek ( $\geq 5 \mathrm{kez} / \mathrm{hafta}$ ) ve en düşük (<1 kez/ay) olan gruplar karşılaştırıldığında bilişsel fonksiyon arasındaki farkın iki yıllık bilişsel yaşlanmaya eşdeğer olduğu sonucuna varılmıştır (32).

\section{DASH Diyeti}

Amerika Birleşik Devletleri Ulusal Sağlık Enstitüsü (National Institutes of Health-NIH), "hipertansiyonun önlenmesi için beslenme yaklaşımı” anlamına gelen DASH diyet modelini 1992 yılında geliştirmiştir. DASH ve Akdeniz diyetinin her ikisinde de bitkisel kaynaklı besinlerin yüksek, kırmızı etin sınırlı tüketilmesi önerilmektedir. DASH diyetinde özellikle kan basıncını düşürmek için potasyum (K), kalsiyum (Ca), magnezyum $(\mathrm{Mg})$ ve posadan zengin besinlerin fazla, doymuş yağ ve şeker içeriği yüksek besinlerin ise sınırlı tüketilmesine ve günlük sodyum $(\mathrm{Na})$ alımının $\leq 2300 \mathrm{mg}$ ile sinırlandırılmasına odaklanılmaktadır (33).

DASH diyeti; yüksek kan basıncı ve düşük dansiteli lipoprotein (LDL) kolesterol düzeyi gibi kardiyovasküler risk faktörlerinin, oksidatif stres, inflamasyon ve insülin direnci gibi patolojik süreçlerin modülasyonunu sağlayarak, demans ve Alzheimer hastalığı gelişimine karşı olumlu etki göstermektedir (13). Prospektif epidemiyolojik bir çalışmada ortalama yaşı 81.5 yll olan 826 birey, 4.1 yll takip edilmiş, Akdeniz ve DASH diyetine uyumu yüksek olan bireylerin daha iyi bilişsel fonksiyona sahip olduğu bulunmuştur (34). Altmış beş yaş üzeri 3831 katılımcının 11 yıl boyunca takip edildiği başka bir çalışmanın sonucunda Akdeniz ve DASH diyetine uyum skoru en yüksek olan grubun bilişsel test skoru, en düşük uyum gösteren gruptan daha yüksek bulunmuştur. Aynı çalışmanın sonuçları tam tahıl, sert kabuklu yemişler ve kurubaklagillerin yüksek tüketiminin de benzer şekilde daha yüksek bilişsel skorla ilişkili olduğunu göstermiştir (35). Yaş ortalaması 52 yll olan fazla kilolu ya da obez olan sedanter ve yüksek kan basıncına sahip bireyler üç gruba ayrılarak dört ay boyunca bir gruba sadece DASH diyeti verilmiş, ikinci gruba DASH diyeti ile birlikte enerji kısıtlaması ve egzersiz müdahalesi yapılmış, üçüncü gruba ise hiçbir müdahale yapılmamıştır. DASH diyeti ile 
birlikte enerji kısıtlaması ve egzersiz müdahalesi yapılan grupta yürütücü işlev, bellek, öğrenme ve psikomotor hızda iyileşme olurken, sadece DASH diyeti alan katılımcllar ise kontrol grubundan daha iyi psikomotor aktivite göstermiştir (36). Buna göre DASH diyetinin enerji kısıtlaması ve egzersizi içeren vücut ağırlık yönetimi ile birlikte uygulanmasının özellikle fazla kilolu ve obez hipertansif bireylerde, bilişsel fonksiyonda daha etkili olabileceği sonucuna varılmıştır (36). Prospektif bir çalışmada ise 65-79 yaş grubundaki 7479 kadın dokuz yıl boyunca takip edilmiş, diyet ile $\mathrm{Na}$ alımı ve hafif bilişsel bozukluk ve Alzheimer Hastalığı gelişme riski arasında ilişki bulunamamıştır. Ancak hipertansiyon tanısı olan ve kan basıncı kontrolü sağlanamayan ( $\geq 140 / 90$ mmHg) bireylerde bilişsel fonksiyonda azalma riski artmıştır (37).

\section{MIND Diyeti}

Nörodejeneratif Gecikme için Akdeniz-DASH Müdahalesi (Mediterranean-DASH Intervention for Neurodegenerative Delay) olarak adlandırılan MIND diyeti, Akdeniz ve DASH diyet bileşenlerinin bir karmasıdır. Morris et al. (38) tarafindan oluşturulan, özellikle bilişsel sağlık ile ilişkili bulunan 10 besin grubunun (yeşil yapraklı sebzeler, diğer sebzeler, sert kabuklu yemişler, çilekgiller, kurubaklagiller, tam tahıllar, deniz ürünleri, kümes hayvanları, zeytinyağı, kırmızı şarap) tüketiminin önerildiği ve beş besin grubunun (kırmızı et, tereyağı ve margarin, peynir, pastane ürünleri ve şekerlemeler, kızartmalar, fast-food besinler) kısıtlanmasını içeren bir diyet modelidir (Tablo 2) (38).

Akdeniz ve DASH diyetinde önerilen yüksek sebzemeyve tüketimi yerine MIND diyetinde özellikle yeşil yapraklı sebzelerin ve çilekgillerin tüketiminin artırılması vurgulanmaktadır. Yeşil yapraklı sebzeler; $\mathrm{K}$ vitamini (fillokinon), folat, lutein, $\beta$-karoten, nitrat, kamferol ve $\alpha$-tokoferolün doğal kaynağıdır (8). Rush Memory and Aging Project çalışmasında, günde 1-2 porsiyon yeşil yapraklı sebze tüketenlerde hiç tüketmeyenlere ya da çok seyrek tüketenlere kiyasla bilişsel yaşlanmanın daha yavaş olduğu ve bu farkın 11 yıla eşdeğer olduğu gözlenmiştir (25). Aynı çalışmanın verilerine göre $\beta$-karoten dışındaki besin ögesi ve biyoaktif bileşenlerden fillokinon, lutein, nitrat, folat, a-tokoferol ve kamferol alımı yüksek olanlarda da bilişsel yaşlanma daha yavaş bulunmuştur (25). MIND diyeti ile ilgili ilk veriler 2015 yılında yayınlanmıştır. Yaşları 58-98 yıl aralığında olan 923 bireyin 4.5 yıl takibi sonucunda, MIND diyete uyumu yüksek olan bireylerde Alzheimer riskinin \%53 oranında, diyetinde llımlı değişiklikler yapan bireylerde ise \%35 oranında azaldığı saptanmıştır (39). Hemşireler Sağlık Çalışması (Nurses’ Health Study-NHS) verilerinin kullanıldığ bir çalışmada, 70 yaş üzeri 16.058 kadın altı yıl takip sonrası uzun dönem MIND diyetine uyumun daha iyi sözel bellek skoru ile ilişkili olduğu gösterilmiştir (40). Bir başka çalışmada MIND diyet skoru yüksek olan bireylerin bilişsel yaşı en düşük skora sahip olanlarla

Tablo 2. MIND diyetinde önerilen ve sınırlandırılması gereken besin grupları (38)

\begin{tabular}{ll}
\hline Beyin sağlığı ile ilgili önerilen $\mathbf{1 0}$ besin grubu & Sınırlandırılması önerilen $\mathbf{5}$ besin grubu \\
\hline Yeşil yapraklı sebzeler & Kırmızı et \\
Diğer sebzeler & Tereyağı- Margarin \\
Sert kabuklu yemişler & Peynir \\
Çilekgiller & Pastane ürünleri, şekerlemeler \\
Kurubaklagiller & Kızartmalar, fast-food besinler \\
Tam tahıllar & \\
Deniz ürünleri & \\
Kümes hayvanları & \\
Zeytinyağı & \\
Kırmızı şarap & \\
\hline
\end{tabular}


karşılaştırıldığında 7.5 yıl daha genç bulunmuş ve bilişsel fonksiyonun azalmasını önlemede MIND diyet skorunun, Akdeniz ve DASH diyet skorlarından daha koruyucu olduğu gösterilmiştir (38).

\section{SONUÇ VE ÖNERILLER}

Bilişsel yaşlanma sürecinin yavaşlatılması konusunda diyet modelleri ile ilgili yapılan araştırmalar çoğunlukla gözlemsel çalışmalardan oluşmakta olup geniş çaplı, uzun süreli klinik çalışmaların sayısı daha azdır. Mevcut kanıtlar, bilişsel fonksiyonun korunmasında; Akdeniz diyeti gibi sağlıklı diyet modellerinin, tek başına bir besin ya da besin grubuna göre daha etkili olduğunu göstermektedir. Bitkisel kaynaklı besinlerin, özellikle MIND diyetinde de vurgulanan yeşil yapraklı sebzeler ve çilekgillerin ağırlıklı olduğu, kırmızı et yerine balık tüketiminin artırıldığı, basit şeker ve işlenmiş besinlerin azaltıldığı diyet modellerinin bilişsel fonksiyonun korunmasinda, demans ve Alzheimer hastalığının gelişiminin önlenmesinde yardımcı olabileceği bildirilmiştir. Bilişsel fonksiyonun korunmasında diyet stratejileri; yaşam boyu sağlıklı diyet modellerinin tercih edilmesi, antioksidan besin ögelerinin yeterli alımı, besin ögesi yetersizliklerinin (B grubu vitaminler, D vitamini) önlenmesi şeklinde özetlenebilir. Diğer yandan bilişsel sağlığı etkileyen fiziksel aktivite, bilişsel eğitim ve kardiyovasküler risk faktörlerinin kontrolü gibi diğer etmenler de göz ardı edilmemelidir. Bilişsel sağlığın korunmasında; sağlıklı diyet modelleri tercih edilmeli ve farklı kültürlere sahip popülasyonlar için ulusal beslenme rehberlerine uyum sağlayacak şekilde geliştirilerek uygulanabilirliği arttırılmalıdır.

Çıkar çatışması - Conflict of interest: Yazarlar çıkar çatışması olmadığını beyan ederler. - The authors declare that they have no conflict of interest.

\section{KAYNAKLAR}

1. World Health Organization, Ageing and Health 2018. Available at: https://www.who.int/news-room/factsheets/detail/ageing-and-health Accessed September 12, 2020.
2. Türkiye İstatistik Kurumu (TÜIK). İstatistiklerle Yaşllar, 2018. Erişim: http://tuik.gov.tr/PreHaberBultenleri. do?id=30699 Erişim tarihi: 12 Eylül 2020.

3. Baumgart M, Snyder HM, Carrillo MC, Fazio S, Kim $\mathrm{H}$, Johns H. Summary of the evidence on modifiable risk factors for cognitive decline and dementia: A population-based perspective. Alzheimers Dement. 2015;11(6):718-26.

4. Norton S, Matthews FE, Barnes DE, Yaffe K, Brayne C. Potential for primary prevention of Alzheimer's disease: An analysis of population-based data. Lancet Neurol. 2014;13(8):788-94.

5. Scarmeas N, Anastasiou CA, Yannakoulia M. Nutrition and prevention of cognitive impairment. Lancet Neurol. 2018;17(11):1006-15.

6. Petersson SD, Philippou E. Mediterranean diet, cognitive function, and dementia: A systematic review of the evidence. Adv Nutr. 2016;7(5):889-904.

7. Virmani A, Pinto L, Binienda Z, Ali S. Food, nutrigenomics, and neurodegeneration-neuroprotection by what you eat! Molecular Neurobiology. 2013;48(2):353-62.

8. Solfrizzi V, Custodero C, Lozupone M, Imbimbo BP, Valiani V, Agosti P, et al. Relationships of dietary patterns, foods, and micro- and macronutrients with Alzheimer's disease and late-life cognitive disorders: A systematic review. J Alzheimers Dis. 2017;59(3):815-49.

9. Dilberger B, Passon M, Asseburg H, Silaidos CV, Schmitt F, Schmiedl T, et al. Polyphenols and metabolites enhance survival in rodents and nematodes-impact of mitochondria. Nutrients. 2019;11(8):1886.

10. Dixit S, Bernardo A, Walker JM, Kennard JA, Kim GY, Kessler ES, et al. Vitamin C deficiency in the brain impairs cognition, increases amyloid accumulation and deposition, and oxidative stress in APP/PSEN1 and normally aging mice. ACS Chem Neurosci. 2015;6(4):57081.

11. Nooyens AC, Milder IE, van Gelder BM, Bueno-deMesquita HB, van Boxtel MP, Verschuren WM. Diet and cognitive decline at middle age: The role of antioxidants. Br J Nutr. 2015;113(9):1410-7.

12. Nooyens ACJ, van Gelder BM, Bueno-de-Mesquita HB, van Boxtel MPJ, Verschuren WMM. Fish consumption, intake of fats and cognitive decline at middle and older age: The Doetinchem Cohort Study. Eur J Nutr. 2018;57(4):1667-75.

13. Abbatecola AM, Russo M, Barbieri M. Dietary patterns and cognition in older persons. Current Opinion in Clinical Nutrition \& Metabolic Care. 2018;21(1):10-3.

14. Trichopoulou A, Kyrozis A, Rossi M, Katsoulis M, Trichopoulos D, La Vecchia C, et al. Mediterranean diet and cognitive decline over time in an elderly Mediterranean population. Eur J Nutr. 2015;54(8):131121. 
15. Limongi F, Noale M, Gesmundo A, Crepaldi G, Maggi S. Adherence to the Mediterranean diet and all-cause mortality risk in an elderly Italian population: Data from the ILSA Study. J Nutr Health Aging. 2017;21(5):505-13.

16. Shannon OM, Stephan BCM, Granic A, Lentjes M, Hayat $\mathrm{S}$, Mulligan A, et al. Mediterranean diet adherence and cognitive function in older UK adults: The European Prospective Investigation into Cancer and Nutrition-Norfolk (EPIC-Norfolk) Study. Am J Clin Nutr. 2019;110(4):938-48.

17. Cherbuin N, Anstey KJ. The Mediterranean diet is not related to cognitive change in a large prospective investigation: The PATH through life study. Am J Geriatr Psychiatry. 2012;20(7):635-9.

18. Chen X, Maguire B, Brodaty H, O’Leary F. Dietary patterns and cognitive health in older adults: A systematic review. J Alzheimers Dis. 2019;67(2):583-619.

19. Valls-Pedret C, Sala-Vila A, Serra-Mir M, Corella D, de la Torre R, Martínez-González MÁ, et al. Mediterranean diet and age-related cognitive decline: A randomized clinical trial. JAMA Internal Medicine. 2015;175(7):1094103.

20. Martinez-Lapiscina EH, Clavero P, Toledo E, Estruch R, Salas-Salvado J, San Julian B, et al. Mediterranean diet improves cognition: The PREDIMED-NAVARRA randomised trial. J Neurol Neurosurg Psychiatry. 2013;84(12):1318-25.

21. Knight A, Bryan J, Wilson C, Hodgson JM, Davis CR, Murphy KJ. The Mediterranean diet and cognitive function among healthy older adults in a 6-month randomised controlled trial: The MedLey study. Nutrients. 2016;8(9):579.

22. Omar SH. Mediterranean and MIND Diets containing olive biophenols reduces the prevalence of Alzheimer's Disease. Int J Mol Sci. 2019;20(11):2797.

23. Hughes TF, Andel R, Small BJ, Borenstein AR, Mortimer JA, Wolk A, et al. Midlife fruit and vegetable consumption and risk of dementia in later life in Swedish twins. The American Journal of Geriatric Psychiatry: Official Journal of the American Association for Geriatric Psychiatry. 2010;18(5):413-20.

24. Barberger-Gateau P, Raffaitin C, Letenneur L, Berr C, Tzourio C, Dartigues JF, et al. Dietary patterns and risk of dementia: The Three-City cohort study. Neurology. 2007;69(20):1921-30.

25. Morris MC, Wang Y, Barnes LL, Bennett DA, DawsonHughes B, Booth SL. Nutrients and bioactives in green leafy vegetables and cognitive decline: Prospective study. Neurology. 2018;90(3):e214-e22.

26. Pastor-Valero M, Furlan-Viebig R, Menezes PR, da Silva SA, Vallada H, Scazufca M. Education and WHO Recommendations for fruit and vegetable intake are associated with better cognitive function in a disadvantaged Brazilian elderly population: A population-based cross-sectional study. PLoS One. 2014;9(4):e94042.

27. Zhang Y, Chen J, Qiu J, Li Y, Wang J, Jiao J. Intakes of fish and polyunsaturated fatty acids and mild-tosevere cognitive impairment risks: A dose-response meta-analysis of 21 cohort studies. Am J Clin Nutr. 2016;103(2):330-40.

28. Gil A, Gil F. Fish, a Mediterranean source of n-3 PUFA: Benefits do not justify limiting consumption. Br J Nutr. 2015;113 Suppl 2:S58-67.

29. Huhn S, Witte AV. Effects of resveratrol on cognitive functions. Nutrition and Functional Foods for Healthy Aging: Elsevier; 2017. p. 283-92.

30. Handing EP, Andel R, Kadlecova P, Gatz M, Pedersen NL. Midlife alcohol consumption and risk of dementia over 43 years of follow-up: A population-based study from the Swedish twin registry. J Gerontol A Biol Sci Med Sci. 2015;70(10):1248-54.

31. Dong L, Xiao R, Cai C, Xu Z, Wang S, Pan L, et al. Diet, lifestyle and cognitive function in old Chinese adults. Arch Gerontol Geriatr. 2016;63:36-42.

32. O’Brien J, Okereke O, Devore E, Rosner B, Breteler M, Grodstein F. Long-term intake of nuts in relation to cognitive function in older women. J Nutr Health Aging. 2014;18(5):496-502.

33. National Institutes of Health, National Heart Lung, and Blood Institute. DASH Eating Plan Available at:https:// www.nhlbi.nih.gov/health-topics/dash-eating-plan Accessed January 10, 2020.

34. Tangney CC, Li H, Wang Y, Barnes L, Schneider JA, Bennett DA, et al. Relation of DASH- and Mediterraneanlike dietary patterns to cognitive decline in older persons. Neurology. 2014;83(16):1410.

35. Wengreen H, Munger RG, Cutler A, Quach A, Bowles A, Corcoran C, et al. Prospective study of Dietary Approaches to Stop Hypertension- and Mediterraneanstyle dietary patterns and age-related cognitive change: The cache county study on memory, health and aging. Am J Clin Nutr. 2013;98(5):1263-71.

36. Smith PJ, Blumenthal JA, Babyak MA, Craighead L, Welsh-Bohmer KA, Browndyke JN, et al. Effects of the dietary approaches to stop hypertension diet, exercise, and caloric restriction on neurocognition in overweight adults with high blood pressure. Hypertension. 2010;55(6):1331-8.

37. Haring B, Wu C, Coker LH, Seth A, Snetselaar L, Manson JE, et al. Hypertension, dietary sodium, and cognitive decline: Results from the women's health initiative memory study. Am J Hypertens. 2016;29(2):202-16.

38. Morris MC, Tangney CC, Wang Y, Sacks FM, Barnes LL, 
Bennett DA, et al. MIND diet slows cognitive decline with aging. Alzheimers Dement. 2015;11(9):1015-22.

39. Morris MC, Tangney CC, Wang Y, Sacks FM, Bennett DA, Aggarwal NT. MIND diet associated with reduced incidence of Alzheimer's disease. Alzheimers Dement. 2015;11(9):1007-14.
40. Berendsen AM, Kang JH, Feskens EJM, de Groot C, Grodstein F, van de Rest O. Association of long-term adherence to the mind diet with cognitive function and cognitive decline in american women. J Nutr Health Aging. 2018;22(2):222-9. 